\title{
Extracranial Vertebral Artery Aneurysm: An Unpleasant Consequence of Neck Massage
}

Sir,

A 25-year-old right-handed gentleman with persistent occipital headache of 5 months' duration noted a progressively enlarging and pulsatile swelling in the right side of the neck (behind the sternocleidomastoid muscle) for the past 4 months' duration [Figure 1]. He had a history of getting a neck and head massage done by his barber periodically and usually clicking sounds 
would be felt by him during manipulation of the neck. Following the last such episode 6 months ago, he developed transient loss of consciousness on the barber's chair for about $15 \mathrm{~min}$ and after recovery complained of severe headache and ataxia for the next few days.

Computed tomography scans of the neck with contrast were done, which showed a large lobulated brilliantly contrast enhancing lesion $(2.5 \mathrm{~cm} \times 2.9$ $\mathrm{cm}$ ) in the right posterior triangle which was having a communication with the right vertebral artery (VA). The enhancing component was surrounded by a hypodense nonenhancing area (approximately $4 \mathrm{~cm} \times 4 \mathrm{~cm}$ ) with areas of differential density in them [Figure 2]. Three-dimensional reconstructions showed very small and indistinct vessels entering and exiting the sac. The aneurysm was located outside the spinal canal and posterior and lateral to the right $\mathrm{C} 1-\mathrm{C} 2$ joint. The distal right VA was small and indistinct compared to the opposite side (left) which was dominant and filling the basilar trunk [Figure 3].

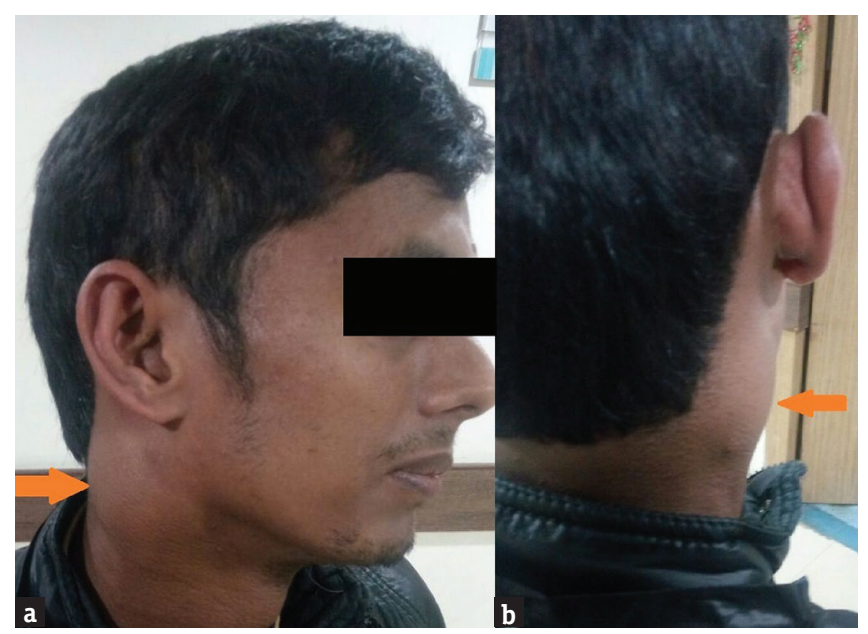

Figure 1: Lateral and posteroanterior clinical photographs of the patient showing a right-sided neck swelling in the posterior triangle

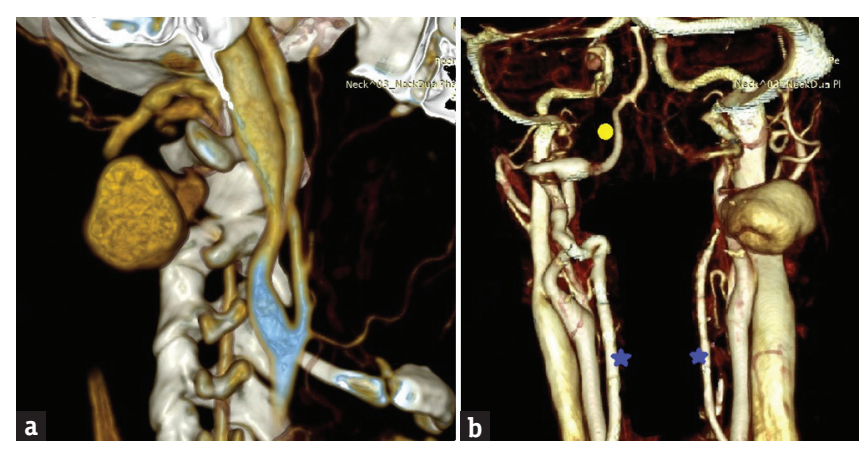

Figure 3: (a) Three-dimensional reconstruction of the aneurysm showing the origin from the vertebral artery is between the $\mathrm{C} 1$ and $\mathrm{C} 2$ foramen transversaria and behind the $\mathrm{C} 1-\mathrm{C} 2$ joint complex and (b) a three-dimensional reconstruction of all neck vessels with both vertebral arteries (blue stars) and the dominant left vertebral artery going on to form the basilar trunk (yellow circle)
The patient underwent unilateral right-sided exposure from $\mathrm{C} 1$ to $\mathrm{C} 3$ laminae and in an approach similar to exposing the $\mathrm{C} 1-\mathrm{C} 2$ joint, sacrifice of right $\mathrm{C} 2$ root was done, and the aneurysm sac was visualized. Soft tissue was mobilized around it and cauterization and disconnection of the VA proximal and distal to the aneurysm were done after which the sac was opened up, clots were removed, and piecemeal excision was done. "Liga" clips (Ethicon) were applied to the stumps of the vessels as a further precaution against postoperative bleeding. Thrombus was sent for histopathological examination. It was found to be laminated with alternate darker and lighter (lines of Zahn) layers composed of red blood cells and platelets and fibrin, respectively [Figure 4].

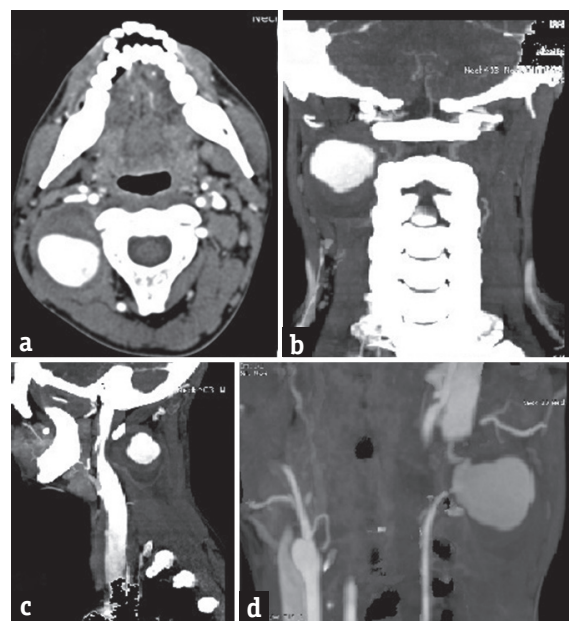

Figure 2: (a) Axial, (b) coronal, and (c) sagittal images showing a brightly enhancing lesion in the right posterior triangle just lateral to the lateral masses of the vertebral bodies. The enhancing component is surrounded by a nonenhancing part that has layering seen inside it, while (d) is a coronal angiographic reconstruction showing the lesion attached to the vertebral artery by slender vessels

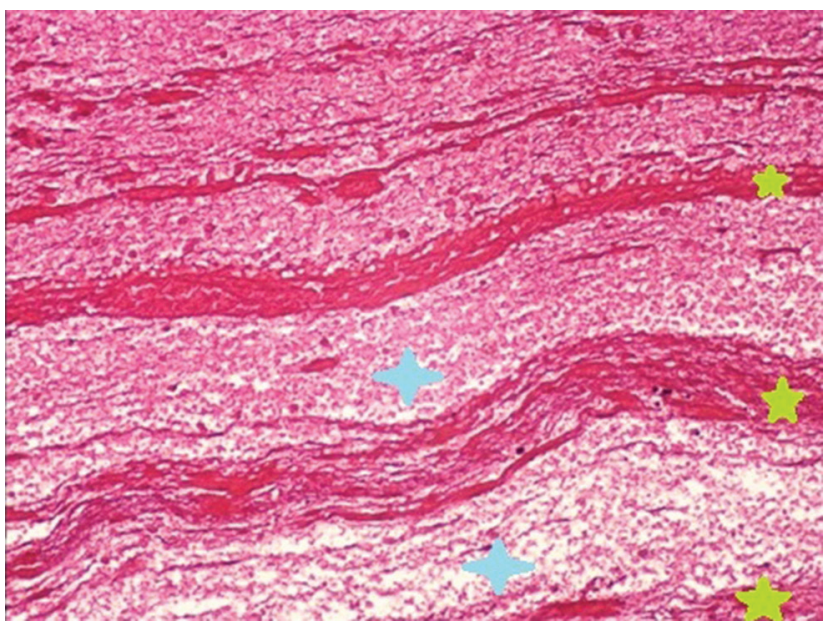

Figure 4: Laminated appearance of the aneurysmal thrombus on microscopy using hematoxylin and eosin stain showing alternate dark and pale lines composed of red blood cells (green stars) and fibrin and platelets (blue stars), respectively 
The patient had an uneventful postoperative recovery and was warned against getting neck manipulation done gain ever in his life as he now had only one patent VA.

Extracranial VA aneurysms are rare and usually occur following trauma. ${ }^{[1,2]}$ They commonly occur as a result of dissection that may be caused by penetrating ${ }^{[1,2]}$ and rarely blunt trauma. ${ }^{[1]}$ Usually, the dissection takes place at the most mobile and unprotected segment of the VA - the atlantal segment (between transverse foramen of $\mathrm{C} 2$ and till it enters the dura). ${ }^{[3]}$ The history our patient gave would suggest that initial passive forcible neck movements during massage led to a VA dissection from which he recovered and later presented with an expanding extracranial VA pseudoaneurysm resulting in $\mathrm{C} 2$ root compression and occipital neuralgia as well as the neck mass.

As with our patient, other reports too describe patients with a pulsatile cervical mass. ${ }^{[2,4]}$ Modes of presentation may vary from cervical radiculopathy, ischemic strokes, subarachnoid hemorrhage, cranial neuropathies, and cerebellar features. ${ }^{[2,5]}$

Treatment modalities include excision of the aneurysm with ligation of the parent vessel,,${ }^{[1,2,5]}$ excision with repair of the VA,,$^{[5,6]}$ arterial bypass with trapping of the aneurysm and excision, ${ }^{[2,6]}$ stenting the vessels,,${ }^{[5]}$ embolization of the aneurysm ${ }^{[3]}$ or parent vessel, ${ }^{[2,5]}$ and flow diverters. ${ }^{[5]}$ Of these, ligation of the VA is the most common procedure undertaken if the contralateral VA is patent. ${ }^{[1]}$

Ganesh Kumar et al. ${ }^{[7]}$ showed that parent vessel sacrifice is an option yielding good outcome in a select group of aneurysms (predominantly vertebral dissecting aneurysms). As the aneurysm, in this case, had a very tenuous proximal inflow and distal outflow, direct repair post exclusion of the aneurysm was not an option. Embolization was ruled out as mass effect of the aneurysm had to be reduced, and bypass was not considered essential as the contralateral VA was filling the vertebrobasilar circulation well. Hence, we proceeded with parent artery occlusion and excision of the partially thrombosed aneurysm.

This case illustrates the need to be aware of the possibility of delayed presentation of a VA dissection in the form of a pulsatile neck mass and the need for a general awareness of the potentially catastrophic consequences sudden, violent neck movements might engender.

\section{Declaration of patient consent}

The authors certify that they have obtained all appropriate patient consent forms. In the form the patient(s) has/have given his/her/their consent for his/her/their images and other clinical information to be reported in the journal. The patients understand that their names and initials will not be published and due efforts will be made to conceal their identity, but anonymity cannot be guaranteed.

\section{Financial support and sponsorship}

Nil.

\section{Conflicts of interest}

There are no conflicts of interest.

Sachinkumar Maheshbhai Patel, Sabyasachi Ojhal, Sayan Das ${ }^{2}$, Prasad Krishnan

Departments of Neurosurgery and ${ }^{1}$ Neurology, National Neurosciences Centre, ${ }^{2}$ Department of Radiology, Peerless Hospital, Kolkata, West Bengal, India

Address for correspondence: Dr. Prasad Krishnan, Department of Neurosurgery, National Neurosciences Centre, Peerless Hospital Campus, II $^{\text {nd }}$ Floor, 360 Panchasayar, Garia, Kolkata - 700 094, West Bengal, India. E-mail: prasad.krishnan@rediffmail.com

\section{REFERENCES}

1. Kao CL, Tsai KT, Chang JP. Large extracranial vertebral aneurysm with absent contralateral vertebral artery. Tex Heart Inst J 2003;30:134-6.

2. Gallo P, Dalacorte A, Raupp E, Santos AJ, Frank MR, Saraiva GA, et al. Giant pseudoaneurysm of the extracranial vertebral artery: Case report. Arq Neuropsiquiatr 1996;54:297-303.

3. Choi MH, Hong JM, Lee JS, Shin DH, Choi HA, Lee K, et al. Preferential location for arterial dissection presenting as golf-related stroke. AJNR Am J Neuroradiol 2014;35:323-6.

4. Nakashima H, Shigemori M, Kikuchi T, Tokutomi T, Kuramoto S. Pseudoaneurysm of the extracranial vertebral artery; a case report. No Shinkei Geka 1991;19:789-93.

5. Stavrinou LC, Stranjalis G, Stavrinou PC, Bontozoglou N, Sakas DE. Extracranial vertebral artery aneurysm presenting as a chronic cervical mass lesion. Case Rep Med 2010;2010:938219.

6. Morasch MD, Phade SV, Naughton P, Garcia-Toca M, Escobar G, Berguer R, et al. Primary extracranial vertebral artery aneurysms. Ann Vasc Surg 2013;27:418-23.

7. Ganesh Kumar N, Ladner TR, Kahn IS, Zuckerman SL, Baker CB, Skaletsky M, et al. Parent vessel occlusion for treatment of cerebral aneurysms: Is there still an indication? A series of 17 patients. J Neurol Sci 2017;372:250-5.

This is an open access journal, and articles are distributed under the terms of the Creative Commons Attribution-NonCommercial-ShareAlike 4.0 License, which allows others to remix, tweak, and build upon the work non-commercially, as long as appropriate credit is given and the new creations are licensed under the identical terms.

\begin{tabular}{|l|l|}
\hline \multicolumn{2}{|c|}{ Access this article online } \\
\hline Quick Response Code: & Website: \\
\hline
\end{tabular}

How to cite this article: Patel SM, Ojha S, Das S, Krishnan P. Extracranial vertebral artery aneurysm: An unpleasant consequence of neck massage. J Neurosci Rural Pract 2018;9:655-7.

(c) 2018 Journal of Neurosciences in Rural Practice | Published by Wolters Kluwer - Medknow 